LIÑO 25. Revista Anual de Historia del Arte. 2019 (pags. 181-186)

\title{
XXIV PREMIOS ASTURIAS DE ARQUITECTURA
}


Carlos Gardel decía en su tango "Volver" que "veinte años no es nada", por lo que, extrapolando, se podría decir que veinticuatro ediciones de un premio como el Asturias de Arquitectura no son "casi nada", aunque la disciplina ha cambiado en estos casi cincuenta años notablemente (los premios son bianuales). Cuando se comenzaron a conceder, los postulados del Movimiento Moderno habían dejado de ser una referencia, había irrumpido el posmodernismo y tras él llegaron otros "ismos" que más pronto que tarde acabaron desapareciendo. En la actualidad no podemos negar que los arquitectos que hoy trabajan, o al menos lo intentan, son hijos del Movimiento Moderno, pero tampoco podemos olvidar que la sociedad ha cambiado y nuevos criterios que antes no tenían una especial relevancia como la sostenibilidad o el reciclaje hoy son tenidos en cuenta. Tras una larga crisis en el sector de la construcción que ya dura más de diez años el modelo profesional necesita replantearse y los trabajos realizados comienzan a traslucir los nuevos aires en la profesión. La figura del arquitecto creador aislado en su estudio es cada vez menos frecuente y la sociedad exige una mayor implicación, evitando endogamias profesionales que se vinieron repitiendo en épocas pasadas.

Es ese motivo, la apertura a la sociedad y la búsqueda de una mayor integración en la misma lo que animó a la actual Junta de gobierno del Colegio Oficial de Arquitectos de Asturias (COAA) a modificar sus premios bianuales. Hasta la fecha se premiaban las construcciones de mayor calidad realizadas en el periodo a valorar y, en ocasiones, algunos trabajos urbanísticos o de investigación, pero no tenían acomodo en los premios otros trabajos realizados por arquitectos que podían ser merecedores de reconocimiento. Así, por ejemplo, quedaban fuera de nuestros galardones colegiales aquellos trabajos que tuvieran como fin la realización del diseño de mobiliario (una ilustre colegiada del COAA es la arquitecta y diseñadora Patricia Urquiola, toda una referencia a nivel mundial) u objetos (relojes, vajillas, diseño textil...). Tampoco eran objeto de valoración alguna los trabajos realizados por nuestros colegiados allende Pajares, ciñéndose el ámbito de actuación de las obras a valorar en territorio astur, algo que se entendía que debía modificarse, pues nos ha tocado vivir en tiempos donde los profesionales que se dedican a esta singular profesión que es la arquitectura han tenido que hacer auténticos

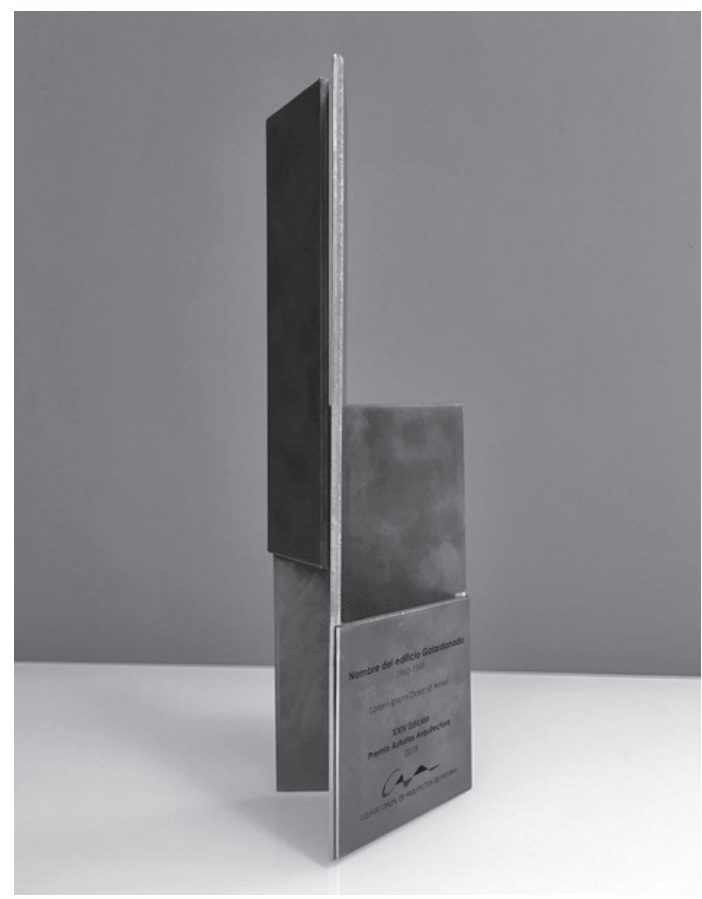

Nuevo trofeo del Premio Asturias de Arquitectura, entregado por primera vez en la XXIV Edición.

malabarismos para poder seguir ejerciéndola y para ello muchos de los compañeros han tenido que buscar los encargos muy lejos de su lugar habitual de residencia. Si esto es así, parece justo que esos trabajos sean también objeto de valoración y reconocimiento.

Buscando dar respuesta a esa pluralidad en el ámbito laboral en la que estamos inmersos se crearon cuatro apartados que pretendían analizar el trabajo realizado por nuestros colegiados en los dos años previos a aquel en el que se convocan los premios. Así se consideraron las siguientes nuevas categorías:

- Premio COAA de Edificación, que distingue la mejor obra de edificación ejecutada, pudiendo ser obra nueva, reforma, rehabilitación, ampliación, etc.

- Premio COAA de Urbanismo, que distingue la mejor propuesta o intervención en materia de Ordenación del Territorio, Urbanismo, Urbanización de Espacios públicos o Paisajismo.

- Premio COAA Otras Arquitecturas, que recompensa los trabajos realizados por arquitectos no contempladas en los casos anteriores (edificación y urbanismo), en campos de actuación tales como el diseño de mobiliario u objetos, publicaciones, montajes de 


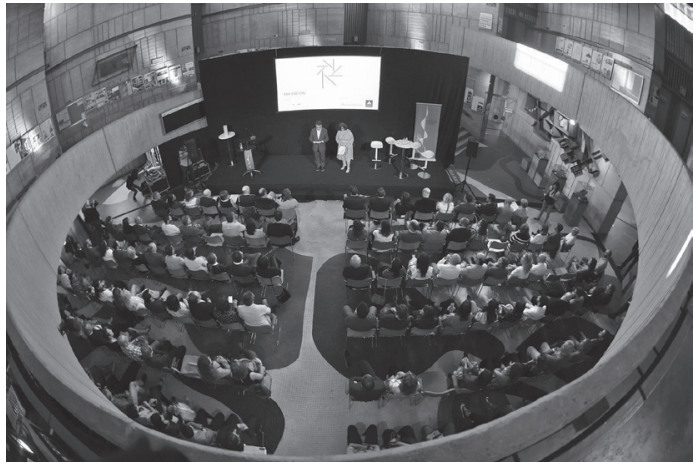

Fotografía del acto de entrega de la XXIV Edición de los Premios Asturias de Arquitectura del COAA

exposiciones, escenografías, páginas webs, revistas, blogs, proyectos Fin de Carrera, Trabajo Fin de Master, Trabajos de investigación, Tesis Doctorales o cualquier otra actividad igualmente relevante.

- Premio COAA Sin Fronteras para un trabajo realizado fuera del Principado de Asturias por arquitectos colegiados en el COAA en el momento de ejecución de la obra objeto de valoración.

Cada categoría tendría un vencedor y si el jurado lo estimara oportuno los correspondientes accésit hasta un número máximo de 3 .

Entre todos los trabajos presentados en las cuatro categorías el jurado elegido escogería el mejor trabajo realizado en ese periodo, el cual sería galardonado con el Premio Asturias de Arquitectura, estimándose conveniente mantener la nomenclatura previa atendiendo al reconocimiento social que entre el colectivo ha tenido el mismo.

Con estos criterios y abundando en el deseo del Colegio Oficial de Arquitectos de Asturias de fomentar la calidad y el rigor de la Arquitectura, entendiendo ésta como un hecho cultural de carácter plural y abierto dirigido en todo momento a la sociedad, se convocaron en marzo de 2018 la XXIV Edición de los Premios Asturias de Arquitectura y, a su vez, la I Edición de los Premios COAA de Edificación, de Urbanismo, Otras Arquitecturas y Sin Fronteras.

Por otro lado y buscando una mayor implicación con la sociedad se planteó en colaboración con el periódico de tirada regional $L a$ Nueva España una votación popular paralela a fin de pulsar la opinión del público no es- pecializado que permitiese identificar aquella propuesta que hubiera sido capaz de transmitir a la sociedad los valores de la Arquitectura de manera más eficaz. El ganador de esta votación digital obtendría el denominado Premio del Público, pudiendo la obra y arquitecto o arquitectos premiados optar también al Premio Asturias de Arquitectura. Hasta la pasada edición se realizaba un acto más doméstico y cerrado al ámbito profesional, con una sencilla entrega de premios y una exposición en la sede colegial se ha optado porque miles de personas vean, valoren y se acostumbren a nuevas propuestas arquitectónicas y como experimento sociológico no deja de ser interesante comparar lo que vota el público y aquello que valoran los profesionales. Es cuestión de tiempo que llegue una edición en la que ambos premios coincidan en reconocer un trabajo determinado y será un buen momento para reflexionar sobre los porqués de la aceptación de su propuesta formal y arquitectónica. No se puede olvidar que salvo Frank Lloyd Wright la inmensa mayoría de los trabajos realizados por los maestros de la arquitectura del siglo XX no tuvieron un gran reconocimiento social. Ni Le Corbusier ni Mies van der Rohe consiguieron convencer al ciudadano medio que su propuesta arquitectónica era acorde con los tiempos y que las viviendas con cubierta a dos aguas ya eran algo del pasado, así que cuando ese proyecto llegue en una futura edición del Premio del Público se deberá estar atento a esa propuesta, pues esa conjunción de gustos no es habitual en estos momentos.

En septiembre de 2018 se reunió el jurado que valoró los trabajos, estando formado por: Elisa Valero Ramos, catedrática de la Escuela de Arquitectura de Granada; José Manuel Martínez, doctor y docente en la escuela de Arquitectura de Valladolid; Juan Moriyón, arquitecto ganador del Premio Asturias de Arquitectura; Sonia Puente Landázuri, decana de COAA y Marcos de Balbín Pacios como secretario del COAA, con voz, pero sin voto. Su trabajo consistió en decidir cuáles eran las mejores propuestas entre las 23 obras de edificación, de las que 11 eran viviendas unifamiliares, 2 edificios de vivienda colectiva, 4 edificios singulares y seis adecuaciones de locales. Del total, cinco eran de promoción pública y 18 de promoción privada. En la categoría de Otras arquitecturas las propuestas fueron muy heterogéneas: desde una tesis doctoral, proyecto fin de carrera, publicaciones, dise- 


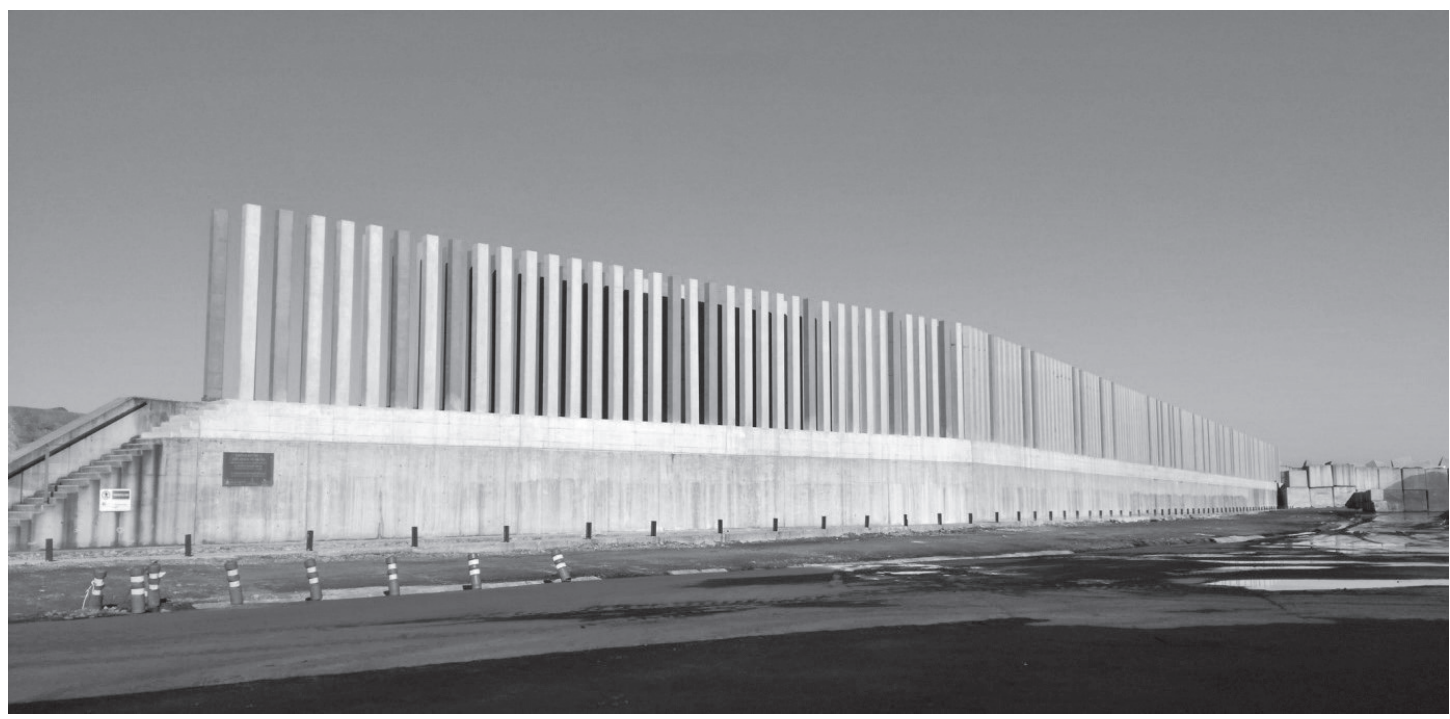

Fotografía de la pantalla de protección contra el viento de Aboño (Abel Alonso González, Arquitecto; Bibiana García Ordiales, Ingeniera) Obra ganadora de la XXIV Edición del Premio Asturias de Arquitectura del COAA

ños de exposiciones o diseño de producto, como por ejemplo un reloj que en la actualidad se está comercializando en Inglaterra y Estados Unidos. Tras la visita a las obras, estudio de los paneles presentados y la consiguiente deliberación se escogieron las obras y arquitectos ganadores, los cuales se darían a conocer un mes más tarde, durante la semana de la arquitectura.

El acto de entrega de los premios se celebró el día 5 de octubre de 2018 y fue otro de los cambios importantes frente a anteriores ediciones. De un acto colegial en la propia sede de Oviedo se pasó a intentar implicar en el mismo al mayor número de personalidades, entidades y empresas que pudieran haber tenido relación con el mundo de la Arquitectura en Asturias. Se escogió como lugar para realizar la entrega de premios el vestíbulo de la facultad de geológicas de la Universidad de Oviedo, realizada en 1969 por Ignacio Álvarez Castelao, obra en la que habían colaborado Antonio Suárez, realizando un maravilloso pavimento y unas sutiles vidrieras de color, y Joaquín Rubio Camín con unos murales metálicos que rinden homenaje a las disciplinas enseñadas en esa Facultad. El motivo de esta elección era doble, por un lado dar a conocer y poner en valor uno de los espacios más interesantes que la arquitectura moderna tiene en la ciudad de Oviedo y, por otro, conseguir que el acto tuviera la ceremonia adecuada para que llegase a tener repercusión en los medios, algo que se consiguió.
La pantalla de protección contra el viento en la explanada de Aboño, realizada por el arquitecto Abel Alonso González y la ingeniera Bibiana García Ordiales, fue la obra ganadora de la XXIV edición del Premio Asturias de Arquitectura. El jurado destacó de esta obra su "calidad paisajística y arquitectónica" y su "alto valor de investigación" como "fruto de una transferencia de conocimiento del campo académico al profesional, que resolvía de forma propositiva, eficaz y brillante, la complejidad de los problemas implicados en el encargo", según constaba en el acta del premio. También se destacó que en esa obra "se apreciaba el trabajo de un equipo pluridisciplinar que con una estrategia inteligente y sensible, había construido una Arquitectura con mayúsculas, desde la sencillez y la atención a problemas reales que afectaban a los ciudadanos".

El arquitecto galardonado, Abel Alonso González, explicó que "más allá de la alegría que siento al recibir este premio, sí quiero decir que en momentos de crisis, surgen las ideas, las propuestas innovadoras. Los arquitectos hacemos más que casitas, podemos colaborar con otras profesiones, ofrecer un punto de vista que mejora las cosas". Y añadió que "con esta obra, hemos puesto nuestro granito de arena para lograr un entorno mejor. Me siento muy satisfecho".

El otro premio de nuevo cuño, el COAA de Edificación, fue concedido a la rehabilitación del edificio de la antigua Escuela de Comer- 


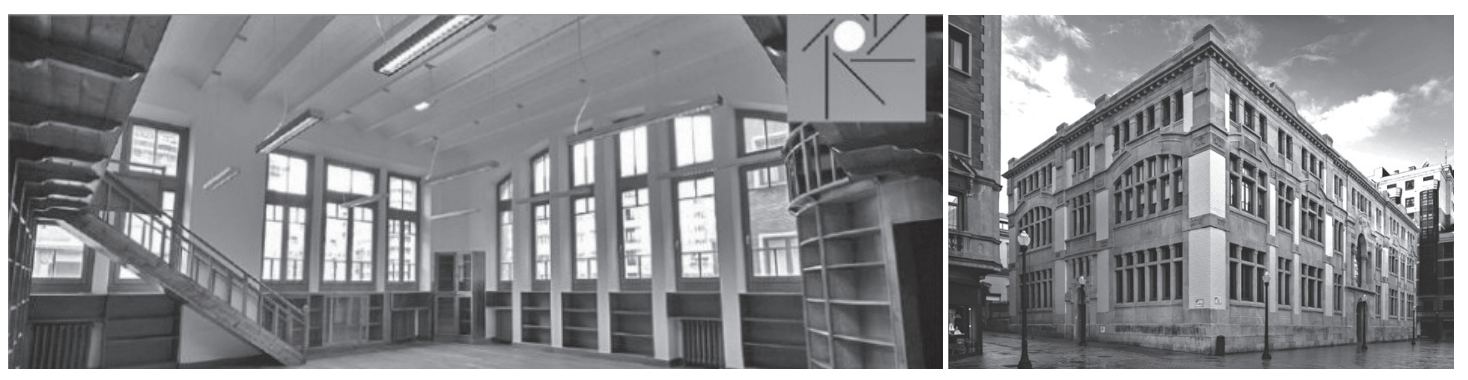

Imágenes de la rehabilitación del edificio de la antigua Escuela de Comercio de Gijón, de los arquitectos Javier Uría de la Fuente, María López Castro, Mónica Costales Rodríguez, Ramón Ruiz Fernández y Jorge Alonso Nicieza, Premio COAA de Edificación.
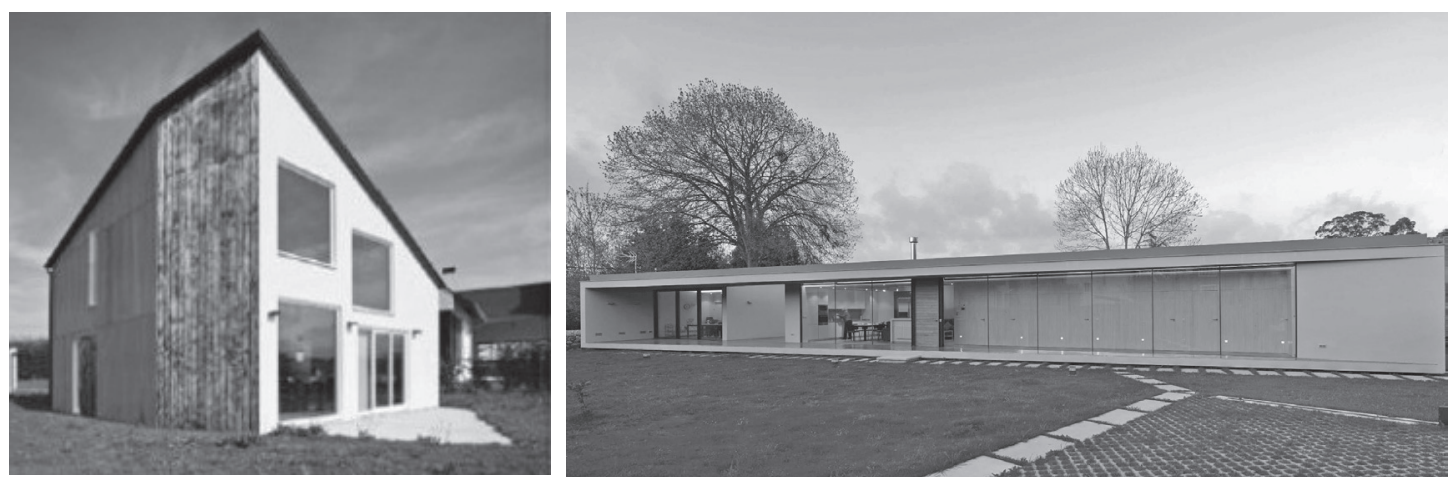

Fotografía de la izquierda: vivienda unifamiliar aislada Cabaña Z, realizada José Ángel Vior Alonso, en Tapia de Casariego; fotografía de la derecha: vivienda unifamiliar aislada en Pancar, de los arquitectos Ester Roldán y Victor Longo. Ambas obras fueron Accésit en la categoría de Edificación.

cio de Gijón, de los arquitectos Javier Uría de la Fuente, María López Castro, Mónica Costales Rodríguez, Ramón Ruiz Fernández y Jorge Alonso Nicieza. Se reconoció en esta obra la gran calidad arquitectónica de una intervención que puso en valor un edificio de un arquitecto, Manuel del Busto (1874-1948), y un periodo significativo en la historia de la arquitectura asturiana y, a la vez, fue capaz de conjugar el respeto a lo existente y la contemporaneidad de la intervención. Además, valoraron positivamente la contención de recursos expresivos y coherencia, así como la adecuación funcional de los espacios resultantes.

Se concedieron en esta categoría dos accésit: a la vivienda unifamiliar aislada Cabaña Z, realizada José Ángel Vior Alonso, en Tapia de Casariego y a la vivienda unifamiliar aislada en Pancar, de los arquitectos Ester Roldán y Victor Longo.

El Premio Otras Arquitecturas fue también para la Pantalla de protección contra el viento en la explanada de Aboño, de Abel Alonso González, concediéndose un accésit a la página web arquitecturadeasturias.com, de la que se valoró el importante trabajo realizado para dar a conocer la arquitectura asturiana a través de

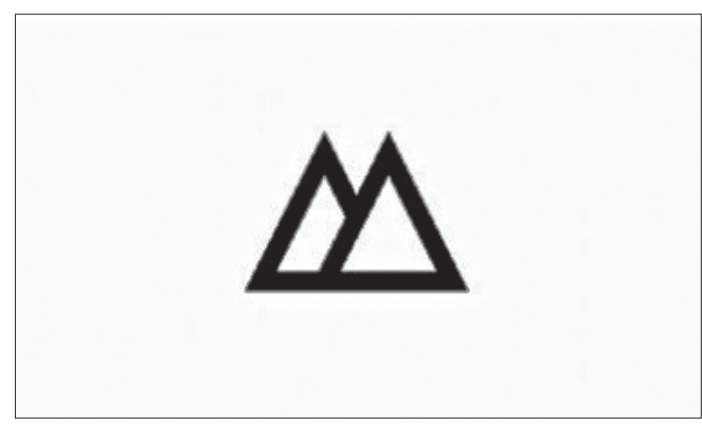

Logotipo de la página web arquitecturadeasturias.com, Accésit Premio COAA Otras Arquitecturas.

la red, poniendo a disposición de los usuarios un inventario de obras ordenado por autores, localización, y uso. Esta web es obra de Omar Rodríguez Mayo, Sara Agúndez Mosquera, Andrea Álvarez Guardado, Ana Gómez Fernández, Silvia Menéndez Riesgo, Luis Manuel Santalla Blanco, Rubén Ulloa Montes y Darío Vallina Rodrigo

El Premio del Público, seleccionado en colaboración con el diario La Nueva España a través de los votos de sus lectores en la página web del periódico, recayó en las 117 viviendas de protección VPP en Mieres, realizado por los 


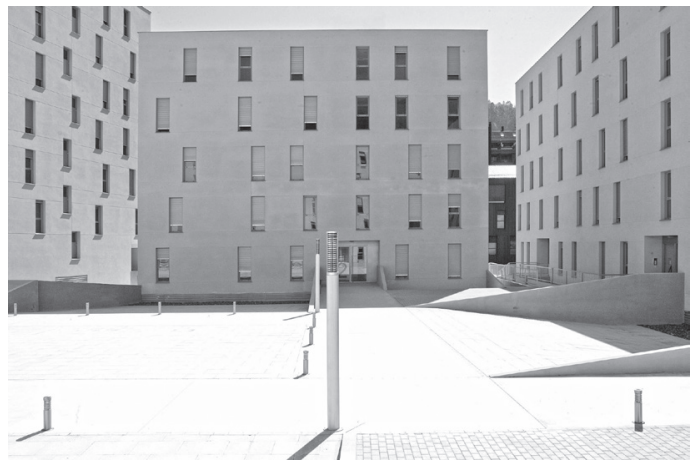

Imagen de las 117 viviendas de protección VPP en Mieres, realizado por los arquitectos Pedro Quero Motto y Susana Solís García, Premio del Público en colaboración con La Nueva España.

arquitectos Pedro Quero Motto y Susana Solís García.

Los premios COAA de Urbanismo y Sin Fronteras no recibieron propuestas, por lo que quedaron desiertos, aunque sí se hizo un especial reconocimiento al arquitecto urbanista Ramón Fernández Rañada, quien había obtenido unos meses antes a propuesta del COAA el premio Nacional de Urbanismo por sus trabajos de protección del litoral asturiano. Se invitó a nuestro compañero a subir al escenario y aunque suele ser parco en palabras el marco y el cariño que se le ofrecieron debieron llegarle pues estuvo en el estrado mucho más tiempo de lo que suele ser habitual en él en este tipo de intervenciones públicas.

En el acto de entrega participaron Rosa Ana Menéndez Duarte, decana de la Facultad de Geología; Wenceslao López Martínez, alcalde de Oviedo; Marta Hernando Álvarez, vicerrectora de Recursos Materiales y Tecnológicos de la Universidad de Oviedo; Juan José Adolfo Fernández Pereiro, director general de Ordenación del Territorio y Urbanismo del Gobierno del Principado de Asturias; Lluís Comerón Graupera, presidente del Consejo Superior de Colegios de Arquitectos de España y Sonia Puente Landázuri, decana del COAA.

En su intervención, Puente Landázuri explicó que "la arquitectura da valor añadido al entorno y a la sociedad que la construye, pero no se produce por generación espontánea, responde a un contexto que lo permite". En este sentido, añadió que "si queremos tener arqui- tectura, con el retorno en términos de cultura, prosperidad, y calidad de vida que conlleva, debemos reconstruir el marco profesional que lo facilite". "La precariedad, las prisas y la falta de confianza, convierten a la buena arquitectura en un milagro singular, casi heroico", dijo y añadió que "nosotros queremos que la arquitectura no sea un acto heroico, sino el resultado, emergente, de una sociedad sana e inteligente que sabe lo que quiere”. También comentó que: "En tiempos de escasez es cuando se vuelve a las esencias, es esta cualidad la que, desde el jurado se ha querido destacar, la arquitectura aplicada a resolver de manera inteligente problemas esenciales", explicó. Puente Landázuri concluyó diciendo que "para pasar del concepto arquitectura como milagro heroico a esa que debe emerger desde la sociedad necesitamos, además, la ineludible complicidad de las administraciones públicas". "Los procedimientos y exigencias normativas y sus malentendidas interpretaciones han convertido a los medios, en fines en sí mismos, relegando a un segundo plano el resultado del objeto contratado".

Citar, por último, que el trofeo del Premio Asturias de Arquitectura tenía también un nuevo diseño. A partir de la insignia que se entrega a los nuevos colegiados realizado según diseño de nuestro añorado compañero Jose Manuel Caicoya el estudio de diseño NegroImpar, quienes habían ganado el concurso del diseño de los trofeos de los premios Castelao y $\mathrm{COAA}+10$, han conseguido convertir el pequeño pin en trofeo al mantener las cualidades compositivas que aquel tiene y proponer los materiales más acordes con la representatividad que debe ofrecer el galardón.

Comienza ahora un nuevo periodo de dos años en los que nuestros colegiados deberán enfrentarse nuevamente al papel en blanco para intentar dar respuesta a las exigencias de los clientes, tendrán que cuadrar presupuestos y solucionar problemas en la obra. Todos esos trabajos se afrontarán con la mayor profesionalidad, pero habrá unos pocos que destacarán sobre el resto. Para ellos ya se está preparando la XXV Edición de los Premios Asturias de Arquitectura. 